Check for updates

Cite this: RSC Adv., 2019, 9, 7356

Received 31st January 2019

Accepted 26th February 2019

DOI: 10.1039/c9ra00853e

rsc.li/rsc-advances

\section{Ethylammonium as an alternative cation for efficient perovskite solar cells from first-principles calculations}

\author{
Diwen Liu, (iD) ac Qiaohong Li (iD) *a and Kechen Wu*ab
}

Mixed-cation lead halide perovskites have emerged as a new class of promising photovoltaic materials for perovskite solar cells. Formamidinium (FA), methylammonium (MA), and Cs cations are widely studied in the field of mixed-cation hybrid halide perovskites. In this work, we have investigated ethylammonium $\left(\mathrm{CH}_{3} \mathrm{CH}_{2} \mathrm{NH}_{3}, \mathrm{EA}\right)$ as an alternative cation to explore the stabilities and electronic properties of mixed $\mathrm{MA}_{1-x} \mathrm{EA}_{x} \mathrm{Pbl}_{3}$ perovskites. The results indicate that replacing $\mathrm{MA}$ with $\mathrm{EA}$ is a more effective way to improve the stabilities of the mixed $M_{A_{1-x}} \mathrm{EA}_{x} \mathrm{Pbl}_{3}$ perovskites except for $\mathrm{MA}_{0.75} \mathrm{EA}_{0.25} \mathrm{Pbl}_{3}$. The band gap of $\mathrm{MA}_{1-x} \mathrm{EA}_{x} \mathrm{Pbl}_{3}$ slightly increases with $x$ from 0.25 to 1.00 , which is quite different from the MA-FA mixed-cation perovskites. The results indicate that the $c$ axis distortion of the $\mathrm{Pb}-\mathrm{I}-\mathrm{Pb}$ bond angles can play a greater role in tuning the band gap. Moreover, the mixed $\mathrm{MA}_{1-x} \mathrm{EA}_{x} \mathrm{Pbl}_{3}$ perovskites show comparable absorption abilities in the visible light region to the pure $\mathrm{MAPbl}_{3}$ structure. We hope that our study will be greatly helpful for further experiments to find more efficient perovskite materials in the future.

\section{Introduction}

Hybrid organic-inorganic lead halide perovskites with outstanding photovoltaic performance have been identified as desirable light absorption materials for perovskite solar cells. ${ }^{1-3}$ The power conversion efficiency of perovskite solar cells has been improved from an intial $3.8 \%{ }^{4}$ to $23.7 \% .^{5}$ In a typical $\mathrm{ABX}_{3}$ perovskite structure, $\mathrm{A}$ is a monovalent cation such as methylammonium $\left(\mathrm{CH}_{3} \mathrm{NH}_{3}{ }^{+}, \mathrm{MA}\right)$, formamidinium $\left(\mathrm{CH}\left(\mathrm{NH}_{2}\right)_{2}{ }^{+}, \mathrm{FA}\right)$, and $\mathrm{Cs}^{+}$. B is a metal ion (usually $\mathrm{Pb}^{2+}$, $\mathrm{Sn}^{2+}$, or $\mathrm{Ge}^{2+}$ ) and $\mathrm{X}$ is a halide anion (usually $\mathrm{I}^{-}, \mathrm{Br}^{-}$, or $\mathrm{Cl}^{-}$). Recently, composition engineering on $\mathrm{ABX}_{3}$ perovskites has been carried out on the cation and halide. This has proved to be a powerful approach to tune the stability and band gap. ${ }^{6-11}$ The most popular cations for composition engineering are Cs, MA, and FA. ${ }^{12-16}$ These works have demonstrated that mixed cations have advantages in improving the stabilities and optoelectronic properties of hybrid perovskites. Therefore, there is a strong desire to explore new stable perovskites with suitable photovoltaic performances.

${ }^{a}$ State Key Laboratory of Structural Chemistry, Fujian Institute of Research on the Structure of Matter, Chinese Academy of Sciences, Fuzhou 350002, P. R. China. E-mail:lqh2382@firsm.ac.cn;wkc@fjirsm.ac.cn; Fax: +8659163173138 ${ }^{b}$ Center for Advanced Marine Materials and Smart Sensors, Minjiang University, Fuzhou 350108, P. R. China

'University of Chinese Academy of Sciences, Beijing 100049, P. R. China
In general, the mixed-cation composition engineering can be evaluated by the Goldschmidt tolerance factor $(t)$, which is defined as follows: ${ }^{17}$

$$
t=\frac{R_{\mathrm{A}}+R_{\mathrm{X}}}{\sqrt{2}\left(R_{\mathrm{B}}+R_{\mathrm{X}}\right)}
$$

where $R_{\mathrm{A}}$ and $R_{\mathrm{B}}$ are the ionic radii of $\mathrm{A}$ and $\mathrm{B}$ cations respectively, and $R_{\mathrm{X}}$ is the ionic radius of the anion. The results suggest that the value of the tolerance factor $t$ could be between 0.81 and $1.11 .^{18}$ To maintain a cubic structure, the ideal $t$ should be close to 1 . When $t>1.11$, the A-site cation is too large and usually precludes the formation of a perovskite. When $t<0.81$, the A-site cation is too small, and this often leads to other structures.

The radius of the ethylammonium cation $\left(\mathrm{CH}_{3} \mathrm{CH}_{2} \mathrm{NH}_{3}, \mathrm{EA}\right)$ is about $2.3 \AA{ }^{19}$ which is greater than that of MA $(1.8 \AA)$ but smaller than that of FA (2.6 $\AA$ ). ${ }^{20}$ Based on the eqn (1), the tolerance factor of $\mathrm{MA}_{1-x} \mathrm{EA}_{x} \mathrm{PbI}_{3}$ ranges from 0.83 to 0.94, as shown in Fig. 1. The tolerance factors of the $\mathrm{MA}_{1-x} \mathrm{EA}_{x} \mathrm{PbI}_{3}$ perovskites are consistent with the relevant conclusions. ${ }^{18}$ This indicates that incorporating EA into $\mathrm{MAPbI}_{3}$ is a effective way to form stable mixed-cation $\mathrm{MA}_{1-x} \mathrm{EA}_{x} \mathrm{PbI}_{3}$ perovskites. However, the $\mathrm{EAPbI}_{3}$ structure was synthesized in $2012 .{ }^{21}$ Its structure was described as a $2 \mathrm{H}$ perovskite type with a larger band gap of $2.2 \mathrm{eV}^{21,22}$ The incorporation of EA cations with larger effective radius to improve material stability has been investigated experimentally. ${ }^{19,23,24} \mathrm{~A}$ small amount of EA cations $(x \leq 0.3)$ have been successfully incorporated into $\mathrm{MAPbI}_{3}$ to form the stable mixed $\mathrm{MA}_{1-x} \mathrm{EA}_{x^{-}}$ $\mathrm{PbI}_{3}$ perovskites. ${ }^{25}$ Recently, a new 3D perovskite with a chemical 


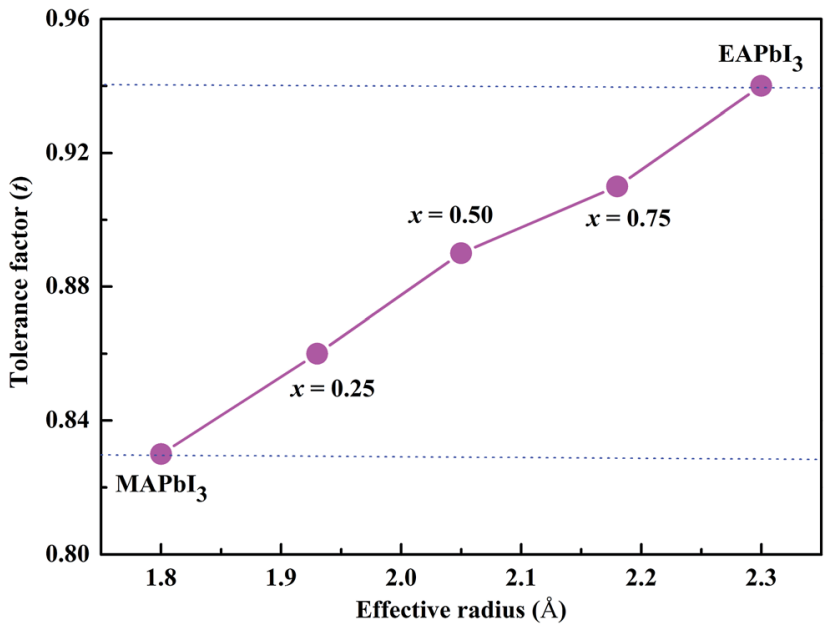

Fig. 1 Correlations between the tolerance factor and the structures of the $\mathrm{MA}_{1-x} \mathrm{EA}_{x} \mathrm{Pbl}_{3}$ perovskites.

structure of $\left(1,3-\mathrm{Pr}\left(\mathrm{NH}_{3}\right)_{2}\right)_{0.5} \mathrm{PbI}_{3}$ was successfully synthesized based on a larger organic cation of propane-1,3-diammonium $\left(1,3-\operatorname{Pr}\left(\mathrm{NH}_{3}\right)_{2}{ }^{2+}\right){ }^{26}$ The results showed that this new perovskite exhibited a tetragonal structure and enhanced stability. ${ }^{26}$ These results indicate that EA as a alternative cation can form a stable 3D perovskite structure under proper experimental conditions. In this work, we have investigated the structural stabilities and electronic properties of MA-EA mixed-cation $\mathrm{MA}_{1-x} \mathrm{EA}_{x} \mathrm{PbI}_{3}$ perovskites, whose electronic properties are substantially different from the MA-FA mixed-cation perovskites.

\section{Computational details}

All of the first-principles calculations were performed with the Vienna Ab initio Simulation Package (VASP) based on
DFT. ${ }^{27}$ The projector-augmented wave method was used for the electron-ion interactions and the Perdew-Burke-Ernzerhof $(\mathrm{PBE})^{28}$ generalized gradient approximation (GGA) ${ }^{29}$ was used to describe the exchange-correlation effect of the electrons. The cut-off energy for the plane wavefunctions was set to $550 \mathrm{eV}$. A Monkhorst-Pack $6 \times 6 \times 6 k$-point mesh over the first Brillouin zone was used for structural optimization and a denser $8 \times 8 \times 8 k$-point mesh was used for the electronic and optical properties. The total energy was converged to $10^{-5} \mathrm{eV}$. The atom coordinates were fully optimized until the residual forces were smaller than $0.01 \mathrm{eV} \AA^{-1}$. It is well known that van der Waals interactions play an important role in hybrid organic-inorganic halide perovskite materials. ${ }^{30,31}$ Thus, the DFT-D3 functional, which includes dispersion interactions, was used for the structural optimization. ${ }^{32}$

It is well known that the PBE functional always underestimated the band gaps of semiconductors. In the previous DFT calculation, our calculated result shows that the band gap of $\mathrm{MAPbI}_{3}$ is $1.50 \mathrm{eV}$ with PBE functional, ${ }^{33}$ which is quite close experimental value of $1.55 \mathrm{eV}^{34}$ Thus, the PBE functional could give the reasonable band gaps for hybrid lead iodine perovskites. Besides, the calculated optical properties of cationdoped $\mathrm{MAPbI}_{3}$ with $\mathrm{PBE}$ functional also can show the right results. Note that DFT-D3 method was adopted to account for van der Waals interactions in all calculations.

To evaluate the stabilities of the pure and mixed perovskites, we calculated the formation energies of the pure and EA-doped $\mathrm{MAPbI}_{3}$ perovskites. The crystal structures of MAI was taken from the ref. 35 The crystal structure of EAI was obtained from monoclinic $(\mathrm{C} 2 / \mathrm{m}) \mathrm{CH}_{3} \mathrm{CH}_{2} \mathrm{NH}_{2} \mathrm{I}^{36}$ with full relaxation of the structural parameters. The stable structure of hexagonal $\mathrm{PbI}_{2}$ was used. The energies of $\mathrm{PbI}_{2}, \mathrm{MAI}$, and

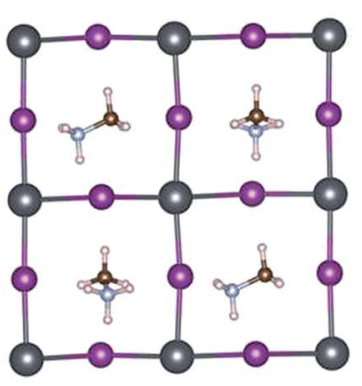

$x=0.00$

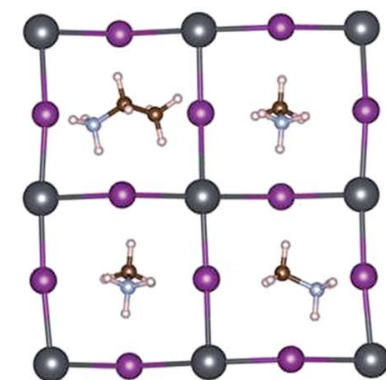

$x=0.25$

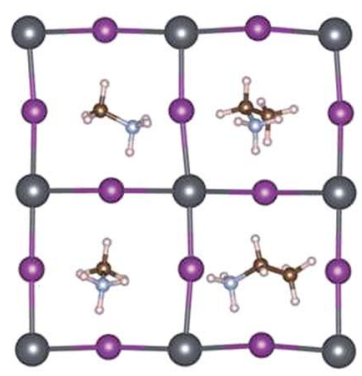

$x=0.50$

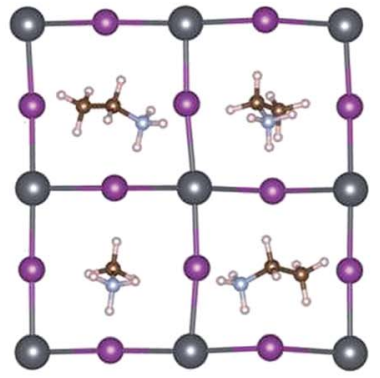

$x=0.75$

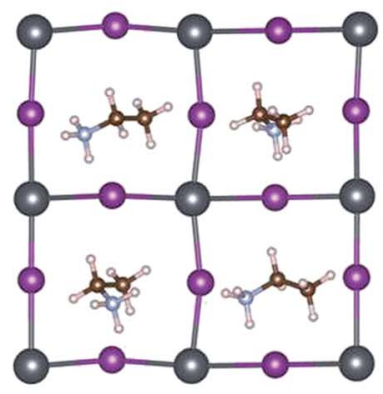

$x=1.00$

Fig. 2 Optimized stable geometries of the mixed $\mathrm{MA}_{1-x} \mathrm{EA}_{x} \mathrm{Pbl}_{3}$ perovskites. 
EAI were calculated using the same computational parameters.

\section{Results and discussion}

\subsection{Geometric structures}

The simulated mixed $\mathrm{MA}_{1-x} \mathrm{EA}_{x} \mathrm{PbI}_{3}$ perovskites are performed by gradually reducing the percentage of MA from the starting $I 4 \mathrm{~cm}$ tetragonal phase. The simulated unit cell contains four $\mathrm{MAPbI}_{3}$ units, so we can simulate three values of the MA-EA ratio, namely $3: 1(x=0.25), 2: 2(x=0.50), 1: 3(x=0.75)$, and the pure phase of $x=0$ and 1 . For $x=0.25,0.50$, and 0.75 , all of the possible substitution sites are considered. The optimized structures of the mixed $\mathrm{MA}_{1-x} \mathrm{EA}_{x} \mathrm{PbI}_{3}$ perovskites are shown in Fig. 2. For the structures with $x=0.50$ and $x=0.75$, all the possible substitution sites are approximately equivalent with the energy differences within $0.02 \mathrm{eV}$. However, the results show that different structures with $x=0.25$ have different stabilities, with calculated maximum energy differences within $0.08 \mathrm{eV}$. The most stable structures of $\mathrm{MA}_{1-x} \mathrm{EA}_{x} \mathrm{PbI}_{3}$ with $x=0.25,0.50$, and 0.75 are chosen to investigate their structural stabilities, electronic and optical properties.

The optimized lattice constants of the mixed $\mathrm{MA}_{1-x} \mathrm{EA}_{x} \mathrm{PbI}_{3}$ perovskites are listed in Table 1 . In the tetragonal $\mathrm{MAPbI}_{3}$ structure, the relaxed lattice constants $a$ is $8.76 \AA$ and $c$ is 12.95 $\AA$, which is good agreement with the experimental results. ${ }^{37}$ The volume slightly increases with increasing EA percentage because of large-size cation doping.

To further evaluate of the stabilities of the pure and mixed perovskites, we calculated the formation energies of the pure and EA-doped perovskites using the following equation:

$$
\begin{aligned}
\Delta H= & E\left(\mathrm{MA}_{1-x} \mathrm{EA}_{x} \mathrm{PbI}_{3}\right)-[(1-x) E(\mathrm{MAI}) \\
& \left.+x E(\mathrm{EAI})+E\left(\mathrm{PbI}_{2}\right)\right]
\end{aligned}
$$

where $E\left(\mathrm{MA}_{1-x} \mathrm{EA}_{x} \mathrm{PbI}_{3}\right), E(\mathrm{MAI}), E(\mathrm{EAI})$, and $E\left(\mathrm{PbI}_{2}\right)$ refer to the formation energies of $\mathrm{MA}_{1-x} \mathrm{EA}_{x} \mathrm{PbI}_{3}, \mathrm{MAI}, \mathrm{EAI}$, and $\mathrm{PbI}_{2}$ phases, respectively. The calculated results for the mixed $\mathrm{MA}_{1-x} \mathrm{EA}_{x} \mathrm{PbI}_{3}$ perovskites are shown in Fig. 3. For $\mathrm{MAPbI}_{3}$, our calculated formation energy is well consistent with the previous calculated values of $-0.01 \mathrm{eV}$ per f.u. ${ }^{38}$ and $-0.02 \mathrm{eV}$ per f.u. ${ }^{39}$ All of the $\Delta H$ values are negative for the $\mathrm{MA}_{1-x} \mathrm{EA}_{x^{-}}$ $\mathrm{PbI}_{3}$ perovskites. This indicates that substituting MA with EA is energetically favourable. Interestingly, the stability of $\mathrm{MA}_{0.75} \mathrm{EA}_{0.25} \mathrm{PbI}_{3}$ is much lower than that of $\mathrm{MAPbI}_{3}$. The similar results were also found for the mixed $\mathrm{MA}_{1-x} \mathrm{Az}_{x} \mathrm{PbI}_{3}$

Table 1 Calculated lattice parameters for the $\mathrm{MA}_{1-x} \mathrm{EA}_{x} \mathrm{Pbl}_{3}$ perovskites

\begin{tabular}{llllr}
\hline$x$ & $a / \AA$ & $b / \AA$ & $c / \AA$ & \multicolumn{1}{c}{$V / \AA^{3}$} \\
\hline 0.00 & 8.76 & 8.76 & 12.95 & 993.74 \\
0.25 & 8.92 & 8.70 & 12.97 & 1005.76 \\
0.50 & 9.05 & 8.67 & 12.98 & 1018.52 \\
0.75 & 9.00 & 8.81 & 13.02 & 1031.69 \\
1.00 & 8.97 & 8.94 & 13.04 & 1045.63
\end{tabular}

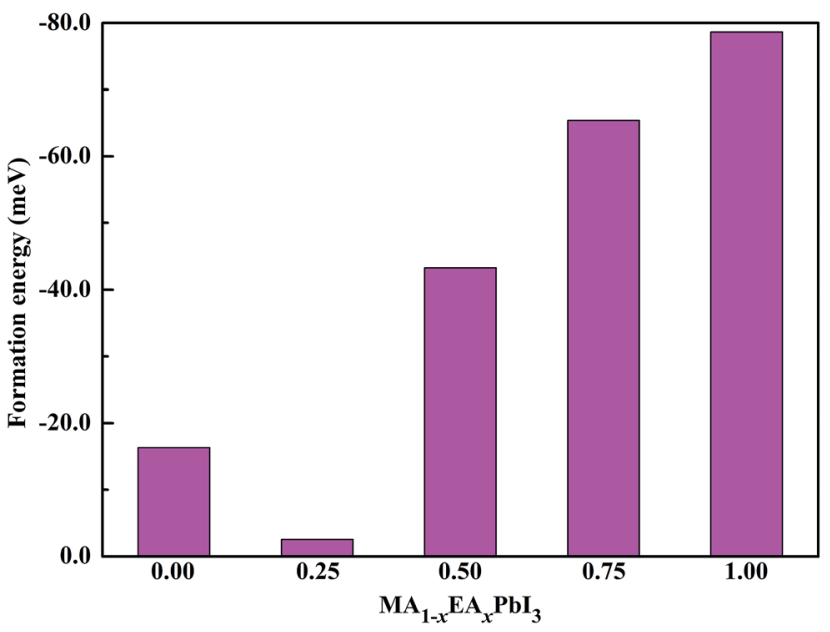

Fig. 3 Calculated formation energies of the $\mathrm{MA}_{1-x} \mathrm{EA}_{x} \mathrm{Pbl}_{3}$ perovskites.

perovskites. ${ }^{33}$ The stabilities of the mixed $\mathrm{MA}_{1-x} \mathrm{EA}_{x} \mathrm{PbI}_{3}$ perovskites are apparently improved when the EA percentage increases from 0.50 to 1.00 .

\subsection{Electronic properties}

To obtain insight into the effect of EA-doped cation on the electronic properties, we performed band structure calculations for all of the structures. Fig. 4 shows the $\mathrm{MA}_{1-x} \mathrm{EA}_{x} \mathrm{PbI}_{3}$ band structures with $x=0.00,0.25,0.50,0.75,1.00$. Notably, regardless of the EA percentage, the band structures of perovskites possess direct bandgaps. The band gap of $\mathrm{MAPbI}_{3}$ at the PBE level is $1.50 \mathrm{eV}$, which agrees well with a previous theoretical result of $1.53 \mathrm{eV}$ (ref. 40) and the experimental value of $1.55 \mathrm{eV}^{34}$ The band gaps are 1.57, 1.61, 1.64, $1.65 \mathrm{eV}$ for $\mathrm{MA}_{1-x} \mathrm{EA}_{x} \mathrm{PbI}_{3}$ with $x=0.25,0.50,0.75$, and 1.00, respectively. However, the band gap of $\mathrm{EAPbI}_{3}$ is much lower than its experimental result $(2.2 \mathrm{eV}) .^{21}$ In fact, an orthorhombic structure in the space group of Pmmn was found for $\mathrm{EAPbI}_{3} \cdot{ }^{21} \mathrm{EAPbI}_{3}$ can form a stable $3 \mathrm{D}$ structure according to its radius. It indicates that the radius of EA may be measured. The band gaps of the mixed $\mathrm{MA}_{1-x} \mathrm{EA}_{x} \mathrm{PbI}_{3}$ perovskites exhibit a slightly increase with EA concentration, which is in good agreement with the experimental results. ${ }^{25}$ However, the results show that the EA incorporation is significantly different from the FA incorporation although the two cations have similar radii. The (1,3$\left.\operatorname{Pr}\left(\mathrm{NH}_{3}\right)_{2}\right)_{0.5} \mathrm{PbI}_{3}$ perovskite also showed a larger band gap $(1.62$ eV) than that of the $\mathrm{MAPbI}_{3}$ structure. ${ }^{26}$ These suitable band gaps of the mixed $\mathrm{MA}_{1-x} \mathrm{EA}_{x} \mathrm{PbI}_{3}$ perovskites, from 1.50 to $1.65 \mathrm{eV}$, makes them highly promising for optoelectronic applications.

To understand the band structure modification, we calculated the projected density of states (PDOS) of the mixed $\mathrm{MA}_{1-x} \mathrm{EA}_{x} \mathrm{PbI}_{3}$ perovskites. Fig. 5 shows the dominant PDOS near the band edgeds of $\mathrm{MA}_{1-x} \mathrm{EA}_{x} \mathrm{PbI}_{3}$ with $x=0.00,0.25$, $0.50,0.75$, and 1.00 . The results indicate that the valence band maximum (VBM) of $\mathrm{MA}_{1-x} \mathrm{EA}_{x} \mathrm{PbI}_{3}$ originates mainly from the $5 \mathrm{p}$ orbital of $\mathrm{I}$. The contribution of the conduction band minimum (CBM) is mainly composed of the $6 \mathrm{p}$ orbital of $\mathrm{Pb}$. 

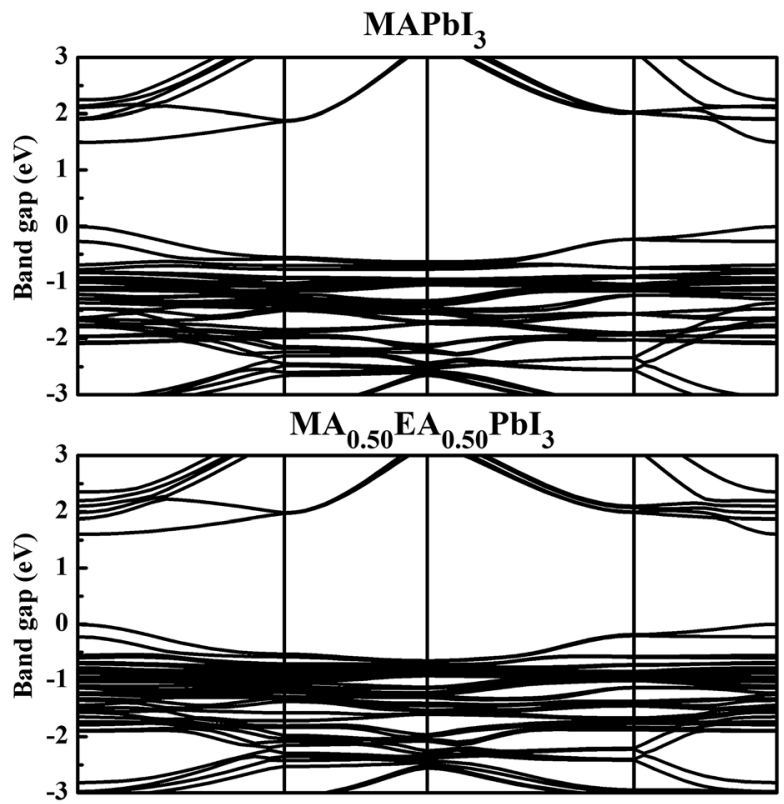

$\mathrm{EAPbI}_{3}$

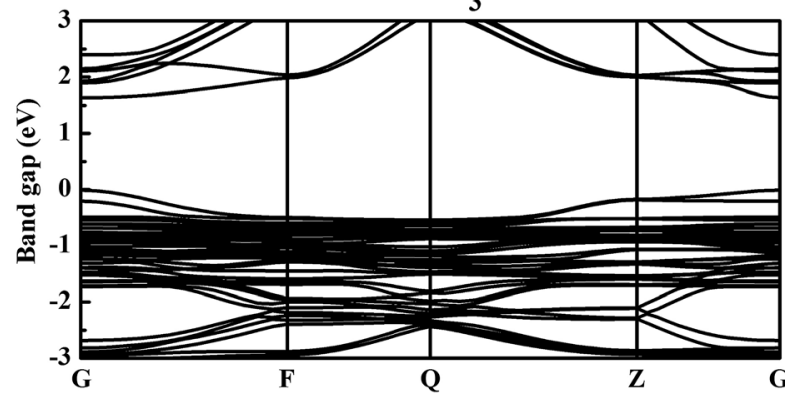

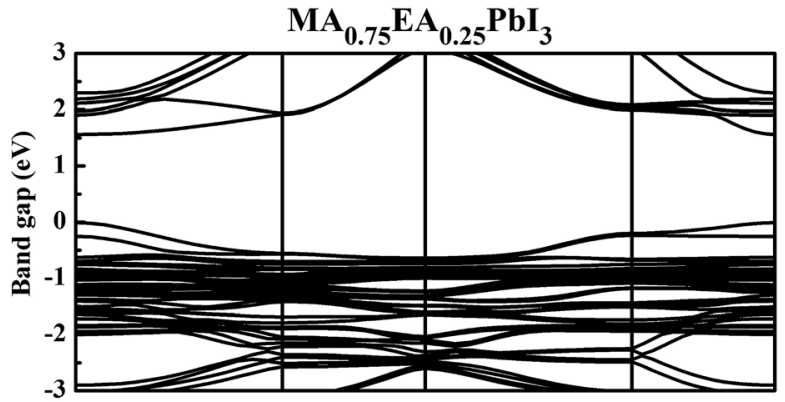

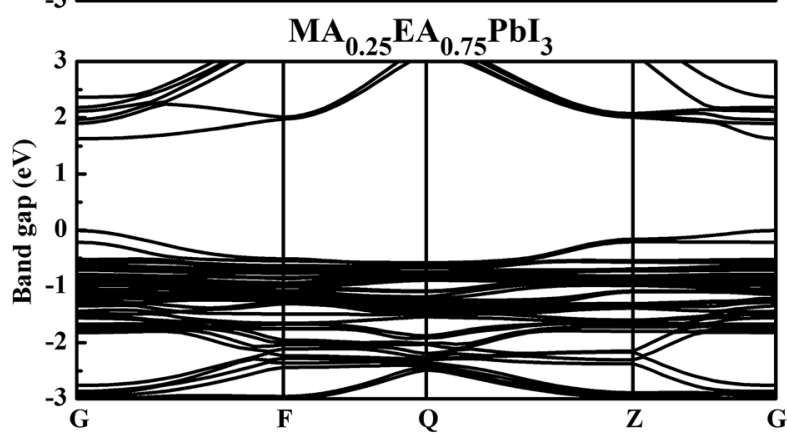

Fig. 4 Calculated band structures of the $\mathrm{MA}_{1-x} \mathrm{EA}_{x} \mathrm{Pbl}_{3}$ perovskites.

The organic cation does not contribute to the band edge states because the states of organic cation are far from the Fermi level.

Previous report has indicated that the electronic structures of hybrid perovskites are affected by structural distortion, and the main factor is the $\mathrm{Pb}-\mathrm{I}-\mathrm{Pb}$ bond angle. ${ }^{41}$ The $\mathrm{Pb}-\mathrm{I}-\mathrm{Pb}$ bond angles of the $\mathrm{MA}_{1-x} \mathrm{EA}_{x} \mathrm{PbI}_{3}$ perovskites are shown in Table 2. The larger distortion of the $\mathrm{Pb}-\mathrm{I}-\mathrm{Pb}$ bond angles is from $a b$ plane. The $\mathrm{Pb}-\mathrm{I}-\mathrm{Pb}$ bond angle from $a b$ plane has little change except for $\mathrm{EAPbI}_{3} . \mathrm{MA}_{0.75} \mathrm{EA}_{0.25} \mathrm{PbI}_{3}$ gives rise to an increased band gap of $1.57 \mathrm{eV}$ compared with the pure $\mathrm{MAPbI}_{3}$ structure. This results indicate that the $c$ axis distortion can play a greater role in tuning the band gap. It can be seen that the change of the $\mathrm{Pb}-\mathrm{I}-\mathrm{Pb}$ bond angles is responsible for the difference in band gaps of the $\mathrm{MA}_{1-x^{-}}$ $\mathrm{EA}_{x} \mathrm{PbI}_{3}$ perovskites.

To get more insight into the electronic properties, we next examine the Bader charge analysis for the pure and mixed perovskites. The results of Bader charge analysis are shown in Table 3. Charge transfer of organic cation and I ion gradually decrease with increasing $x$. However, charge transfer of $\mathrm{Pb}$ cation gradually increases with increasing $x$.

\subsection{Optical properties}

To evaluate the impact of the EA incorporation on the optical performance of MA-EA mixed-cation perovskites, we have calculated the optical absorption coefficient of each structure. The absorption coefficient $I(\omega)$ was given as below: ${ }^{42}$

$$
I(\omega)=\sqrt{2} \omega\left[\sqrt{\varepsilon_{1}(\omega)^{2}+\varepsilon_{2}(\omega)^{2}}-\varepsilon_{1}(\omega)\right]^{1 / 2}
$$

where $\varepsilon_{1}(\omega)$ and $\varepsilon_{2}(\omega)$ represent the real and imaginary parts of the dielectric function depending on the light frequency $\omega$. The absorption spectra of the perovskite compounds are shown in Fig. 6. The optical absorption of $\mathrm{MAPbI}_{3}$ agrees well with the previous result. ${ }^{40}$ It can be seen that the $\mathrm{MA}_{1-x} \mathrm{EA}_{x} \mathrm{PbI}_{3}$ perovskites have slightly weaker absorption than that of $\mathrm{MAPbI}_{3}$ in the range of $300-400 \mathrm{~nm}$, which are attributed to their band gaps. The $\mathrm{MA}_{1-x} \mathrm{EA}_{x} \mathrm{PbI}_{3}$ perovskites show the comparable absorption abilities in the visible light region compared with the pure $\mathrm{MAPbI}_{3}$ perovskite. Based on the stability of material, the $\mathrm{MA}_{1-x} \mathrm{EA}_{x} \mathrm{PbI}_{3}(0.50 \leq x \leq 1.00)$ perovskites can become the potential candidates for efficient perovskite solar cells. 

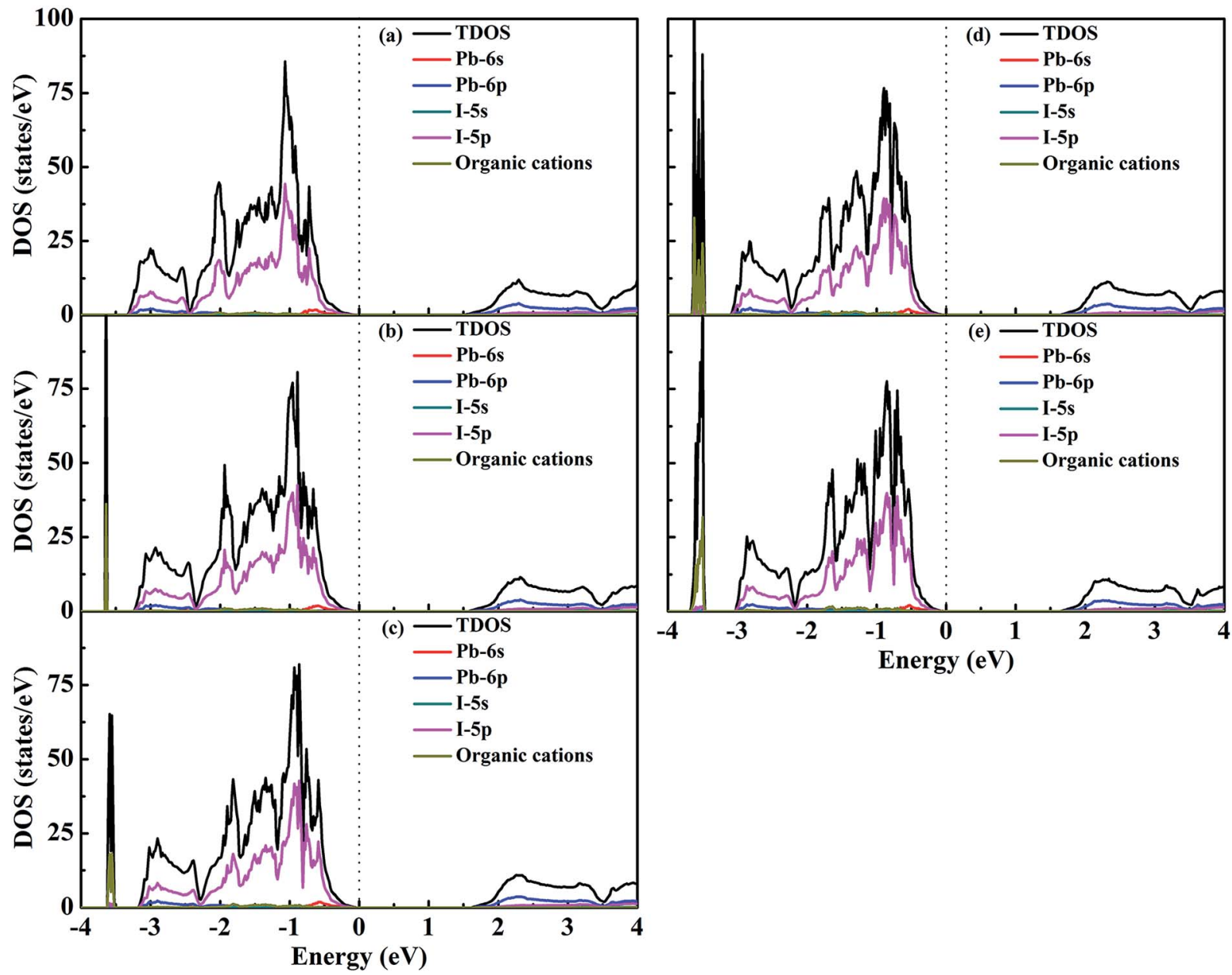

Fig. 5 DOS structures of (a) $\mathrm{MAPbl}_{3}$ (b) $\mathrm{MA}_{0.75} \mathrm{EA}_{0.25} \mathrm{Pbl}_{3}$, (c) $\mathrm{MA}_{0.50} \mathrm{EA}_{0.50} \mathrm{Pbl}_{3,}$ (d) $\mathrm{MA}_{0.25} \mathrm{EA}_{0.75} \mathrm{Pbl}_{3}$, and (e) $\mathrm{EAPbl}_{3}$.

Table $2 \mathrm{~Pb}-\mathrm{I}-\mathrm{Pb}$ bond angles and band gaps of the $\mathrm{MA}_{1-x} \mathrm{EA}_{x} \mathrm{Pbl}_{3}$ perovskites

\begin{tabular}{llll}
\hline & \multicolumn{2}{c}{$\mathrm{Pb}-\mathrm{I}-\mathrm{Pb}$ bond angles $\left(^{\circ}\right)$} & \\
\cline { 2 - 3 }$x$ & $\begin{array}{l}\text { In } a b \\
\text { plane }\end{array}$ & $\begin{array}{l}\text { Along } c \\
\text { axis }\end{array}$ & $E_{\mathrm{g}}(\mathrm{eV})$ \\
\hline 0.00 & 150.0 & 175.6 & 1.50 \\
0.25 & 149.9 & 174.2 & 1.57 \\
0.50 & 149.6 & 171.2 & 1.61 \\
0.75 & 151.2 & 171.0 & 1.64 \\
1.00 & 155.8 & 171.5 & 1.65 \\
\hline
\end{tabular}

Table 3 Bader charge analysis of the $\mathrm{MA}_{1-x} \mathrm{EA}_{x} \mathrm{Pbl}_{3}$ perovskites ( $\mathrm{A}$ represents the organic cation)

\begin{tabular}{llll}
\hline$x$ & $\mathrm{~A}$ & $\mathrm{~Pb}$ & $\mathrm{I}$ \\
\hline 0.00 & +0.727 & +0.941 & -0.556 \\
0.25 & +0.719 & +0.944 & -0.554 \\
0.50 & +0.714 & +0.946 & -0.553 \\
0.75 & +0.710 & +0.947 & -0.552 \\
1.00 & +0.707 & +0.949 & -0.552
\end{tabular}

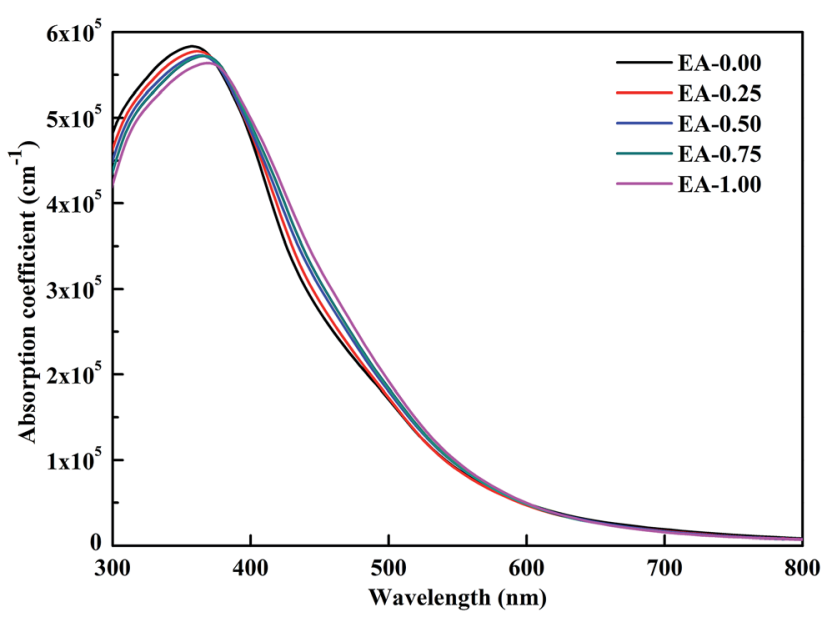

Fig. 6 Calculated optical absorption spectra of the $M_{1-x} E A_{x} P b l_{3}$ perovskites.

\section{Conclusions}

In summary, first-principles calculations based on DFT were carried out on structural stabilities, electronic and optical properties of the mixed $\mathrm{MA}_{1-x} \mathrm{EA}_{x} \mathrm{PbI}_{3}$ perovskites. The results 
indicate that incorporating $\mathrm{EA}$ into $\mathrm{MAPbI}_{3}$ to form mixedcation $\mathrm{MA}_{1-x} \mathrm{EA}_{x} \mathrm{PbI}_{3}$ perovskite is a potentially effective way to improve its stability. The band gap of $\mathrm{MA}_{1-x} \mathrm{EA}_{x} \mathrm{PbI}_{3}$ slightly increases with $x$ from 0.25 to 1.00 , which is quite different from the MA-FA mixed-cation perovskites. The results indicate that the $c$ axis distortion of the $\mathrm{Pb}-\mathrm{I}-\mathrm{Pb}$ bond angles can play a greater role in tuning the band gap. The mixed $\mathrm{MA}_{1-x} \mathrm{EA}_{x} \mathrm{PbI}_{3}$ perovskites show the comparable absorption abilities in the visible light region compared with the $\mathrm{MAPbI}_{3}$ structure. Based on the above results, we hope that our study will be helpful for further experiments to find more efficient perovskite solar cells.

\section{Conflicts of interest}

There are no conflicts to declare.

\section{Acknowledgements}

This work was supported by the National Natural Science Foundation of China (No. 21673240) and the Foreign Cooperation Project of Fujian Province (No. 2017I0019).

\section{References}

1 P. Docampo and T. Bein, Acc. Chem. Res., 2016, 49, 339-346. 2 Q. Lin, A. Armin, P. L. Burn and P. Meredith, Acc. Chem. Res., 2016, 49, 545-553.

3 H. S. Jung and N.-G. Park, Small, 2015, 11, 10-25.

4 A. Kojima, K. Teshima, Y. Shirai and T. Miyasaka, J. Am. Chem. Soc., 2009, 131, 6050-6051.

5 NREL, Best Research-Cell Efficiences chart, https:// www.nrel.gov/pv/assets/pdfs/best-reserch-cell-

efficiencies.pdf.

6 F. Xu, T. Zhang, G. Li and Y. Zhao, J. Mater. Chem. A, 2017, 5, 11450-11461.

7 T. Matsui, J.-Y. Seo, M. Saliba, S. M. Zakeeruddin and M. Grätzel, Adv. Mater., 2017, 29, 1606258.

8 G. Li, T. Zhang, N. Guo, F. Xu, X. Qian and Y. Zhao, Angew. Chem., Int. Ed., 2016, 55, 13460-13464.

9 Z. Shi, Y. Zhang, C. Cui, B. Li, W. Zhou, Z. Ning and Q. Mi, Adv. Mater., 2017, 29, 1701656.

10 C. Yi, J. Luo, S. Meloni, A. Boziki, N. Ashari-Astani, C. Grätzel, S. M. Zakeeruddin, U. Röthlisberger and M. Grätzel, Energy Environ. Sci., 2016, 9, 656-662.

11 M. Saliba, T. Matsui, K. Domanski, J.-Y. Seo, A. Ummadisingu, S. M. Zakeeruddin, J.-P. Correa-Baena, W. R. Tress, A. Abate, A. Hagfeldt and M. Grätzel, Science, 2016, 354, 206-209.

12 W. S. Yang, B.-W. Park, E. H. Jung, N. J. Jeon, Y. C. Kim, D. U. Lee, S. S. Shin, J. Seo, E. K. Kim, J. H. Noh and S. I. Seok, Science, 2017, 356, 1376-1379.

13 H. Bhunia, S. Chatterjee and A. J. Pal, ACS Appl. Energy Mater., 2018, 1, 4351-4358.

14 Z. Li, M. Yang, J.-S. Park, S.-H. Wei, J. J. Berry and K. Zhu, Chem. Mater., 2016, 28, 284-292.
15 D. Ghosh, A. R. Smith, A. B. Walker and M. S. Islam, Chem. Mater., 2018, 30, 5194-5204.

16 J.-W. Lee, D.-H. Kim, H.-S. Kim, S.-W. Seo, S. M. Cho and N.-G. Park, Adv. Energy Mater., 2015, 5, 1501310.

17 H. J. Snaith, J. Phys. Chem. Lett., 2013, 4, 3623-3630.

18 Y. Zhao and K. Zhu, Chem. Soc. Rev., 2016, 45, 655-689.

19 H.-L. Hsu, C.-C. Chang, C.-P. Chen, B.-H. Jiang, R.-J. Jeng and

C.-H. Cheng, J. Mater. Chem. A, 2015, 3, 9271-9277.

20 B. Saparov and D. B. Mitzi, Chem. Rev., 2016, 116, 4558-4596.

21 J.-H. Im, J. Chung, S.-J. Kim and N.-G. Park, Nanoscale Res. Lett., 2012, 7, 353.

22 M. Safdari, A. Fischer, B. Xu, L. Kloo and J. M. Gardner, J. Mater. Chem. A, 2015, 3, 9201-9207.

23 C. Wu, K. Chen, D. Y. Guo, S. L. Wang and P. G. Li, RSC Adv., 2018, 8, 2900-2905.

24 W. Peng, X. Miao, V. Adinolfi, E. Alarousu, O. El Tall, A.-H. Emwas, C. Zhao, G. Walters, J. Liu, O. Ouellette, J. Pan, B. Murali, E. H. Sargent, O. F. Mohammed and O. M. Bakr, Angew. Chem., Int. Ed., 2016, 55, 10686-10690.

25 Y. Wang, T. Zhang, G. Li, F. Xu, T. Wang, Y. Li, Y. Yang and Y. Zhao, J. Energy Chem., 2018, 27, 215-218.

26 C. Ma, D. Shen, M.-F. Lo and C.-S. Lee, Angew. Chem., Int. Ed., 2018, 57, 9941-9944.

27 G. Kresse and J. Furthmüller, Comput. Mater. Sci., 1996, 6, 15-50.

28 P. E. Blöchl, Phys. Rev. B, 1994, 50, 17953-17979.

29 J. P. Perdew, K. Burke and M. Ernzerhof, Phys. Rev. Lett., 1996, 77, 3865-3868.

30 D. A. Egger and L. Kronik, J. Phys. Chem. Lett., 2014, 5, 27282733.

31 Y. Wang, T. Gould, J. F. Dobson, H. Zhang, H. Yang, X. Yao and H. Zhao, Phys. Chem. Chem. Phys., 2014, 16, 1424-1429.

32 S. Grimme, J. Antony, S. Ehrlich and H. Krieg, J. Chem. Phys., 2010, 132, 154104.

33 D. Liu, Q. Li, J. Hu, H. Jing and K. Wu, J. Mater. Chem. C, 2019, 7, 371-379.

34 G. E. Eperon, S. D. Stranks, C. Menelaou, M. B. Johnston, L. M. Herz and H. J. Snaith, Energy Environ. Sci., 2014, 7, 982-988.

35 C. Zheng and O. Rubel, J. Phys. Chem. C, 2017, 121, 1197711984.

36 K. N. Robertson, T. S. Cameron and O. Knop, Can. J. Chem., 1996, 74, 1572-1591.

37 C. C. Stoumpos, C. D. Malliakas and M. G. Kanatzidis, Inorg. Chem., 2013, 52, 9019-9038.

38 R. Ali, G.-J. Hou, Z.-G. Zhu, Q.-B. Yan, Q.-R. Zheng and G. Su, Chem. Mater., 2018, 30, 718-728.

39 D. Yang, J. Lv, X. Zhao, Q. Xu, Y. Fu, Y. Zhan, A. Zunger and L. Zhang, Chem. Mater., 2017, 29, 524-538.

40 P.-P. Sun, Q.-S. Li, L.-N. Yang and Z.-S. Li, Nanoscale, 2016, 8, 1503-1512.

41 Z. Xiao, W. Meng, J. Wang, D. B. Mitzi and Y. Yan, Mater. Horiz., 2017, 4, 206-216.

42 S. Saha, T. P. Sinha and A. Mookerjee, Phys. Rev. B: Condens. Matter Mater. Phys., 2000, 62, 8828-8834. 